\title{
Eco-sustainable routing of power lines for the connection of renewable energy plants to the Italian high-voltage grid
}

\author{
Rodolfo Araneo • Salvatore Celozzi • \\ Chiara Vergine
}

Received: 21 May 2014/Accepted: 23 September 2014/Published online: 11 October 2014

(C) The Author(s) 2014. This article is published with open access at Springerlink.com

\begin{abstract}
Routing of high-voltage electric transmission lines for the connection of renewable energy-distributed generation plants is a critical issue from an environmental point of view. A standard methodology that accounts for multiple perspectives, influence factors and is able to mediate between weighted constraints can be a useful tool for the regulating bodies that are involved in approval processes. The methodology can be an effective support to increase reliability, save consumers' money and mitigate the unavoidable impacts of the lines on the population living nearby. In this paper we investigate the suitability of a procedure employed by Terna, the Italian high-voltage transmission system operator, to identify the corridors where to route new overhead transmission lines with the lowest environmental impact. The methodology is based on the subdivision of all the relevant constraints dictated by environmental issues and territory legislations in four main classes. A real case study concerning the design and connection of a wind farm placed near Collarmele, in the center of Italy, shows the effectiveness of the proposed methodology.
\end{abstract}

Keywords Connection assessment - Overhead power lines - Distributed generation - Wind farm

\footnotetext{
R. Araneo $(\bowtie) \cdot S$. Celozzi

DIAEE, Electrical Engineering Division,

University of Rome "La Sapienza",

Rome, Italy

e-mail: rodolfo.araneo@uniroma1.it

S. Celozzi

e-mail: salvatore.celozzi@uniroma1.it

C. Vergine

National Transmission Network, Terna S.p.A.,

Rome, Italy

e-mail: chiara.vergine@terna.it
}

\section{Introduction}

Governments and companies are investing large efforts in developing technologies to improve clean renewable energy sources $[3,6]$ due to several economic and environmental reasons $[1,4,5,7,12,17,24,29,31,32]$.

The energy savings and the promotion of renewable energy sources are an essential part of the European energy policy $[13,19,21,23,26]$ aimed at ensuring competitiveness, sustainability and security of energy supply, as well as their integration with the best environmental practices to reduce emissions of $\mathrm{CO}_{2}$ and other greenhouse gases [20]. According to the European Energy Roadmap for moving toward a competitive low-carbon economy, a secure, competitive and decarbonized energy system in 2050 is possible [14-16].

In this framework, in recent years, the development of renewable energy in Italy has experienced an extremely strong growth, boosted by an effective incentive system. The GSE, the state-owned company which promotes and supports renewable energy sources in Italy with the Italian Regulatory Authority for Electricity, Gas and Water (AEEG) estimated on December 2011 that nearly 250,000 connection requests had been accepted on April 2011, corresponding to about $196 \mathrm{GW}$ of power. Nevertheless, on closer view of these requests, $42 \mathrm{GW}$ was related to plants already connected, $14 \mathrm{GW}$ to plants under construction and $140 \mathrm{GW}$ to plants that had not yet been approved for construction and operation. This is a clear evidence that the authorization process was, and still is, a decisive step for the construction of a new plant for renewable energy generation. Thus, the feasibility study prior to the beginning of the process itself is even more crucial.

The feasibility of a new plant $[22,25,30]$, especially if its nominal rated power is so high to request a connection 
to the high-voltage (HV) transmission network operated by Terna S.p.A., the Italian Electrical Transmission System Operator, is conditioned by the capability of the network to accept the new power production. This comprises, from a technical point of view, the identification of a new or existing electric substation to which the plant can be connected and the identification of a suitable land corridor through which to route the new transmission line [27, 28]. The proper design of the new connection infrastructure from a prescribed start point to a prescribed end point is the real critical point in the authorization process, rather than the power plant itself.

In fact, it is well-known that local populations are often hostile to the routing of new power lines, because they do not perceive any direct benefit from their installation and have serious concerns about their health, landscape and property values [33-35]. Overhead power lines are large linear elements in the landscape. Their scale is usually much larger than that of objects in close proximity, e.g., houses and trees, so that their major effect is likely to be the visual intrusion of the towers on the corridors through which the lines are routed. Moreover, their construction may disturb sites of natural interest, requiring new access tracks and causing during their life periodic disturbance due to maintenance operations. Consequently, the optimal goal in building new transmission lines is to effectively minimize the negative impacts on people and environment while ensuring safety, reliability and cost savings for the utility.

It has been observed that the existing energy models and research tools usually employed in the design of new plants have low concerns on land use, landscapes and biodiversity. Consequently, it would be difficult to provide comprehensive decision support by using only these tools. However, suitable energy models, ecological assessment models and multi-criteria approaches have been proposed with great potential for interlinking. A comprehensive framework for the assessment of environmental impacts is provided by Strategic Environmental Assessment (SEA), which is developed for environmental impact analysis for policies, plans and programs [18].

In this paper, we investigate the feasibility, from an environmental point of view, of the methodology applied by Terna S.p.A in siting a new overhead power line for a wind farm located in the center of Italy. The methodology is based on the subdivision of all the relevant constraints (dictated by environmental issues and territory legislations) in four classes: Exclusion, Rejection, Problem and Attraction. Consequently, the procedure is named ERPA. The subdivision is performed on structured processes and is based on the use of geographic information systems (GIS) analysis concepts. The GIS system can assemble large data quantities of the various factors into a meaningful analysis outputting the results graphically. The results, either visually or statistically, help to convey the corridor where the new connecting line can be routed at minimum environmental cost.

The ERPA framework enables the inclusion of relevant environmental information into decision making. Within the ERPA framework, the significant constraints on the environment that are taken into account include the specific issues regarding biodiversity, population, human health, soil, water, cultural heritage, landscape and the interrelationships between the above constraints.

\section{The wind farm}

The case study involves the construction of a wind farm with installed capacity of $16 \mathrm{MW}$ placed in the territory of the two municipalities, Cerchio and Aielli, located in the province of L'Aquila in the Italian central region Abruzzo, as shown in Fig. 1. In particular, the new wind farm consists of eight turbines, type Vestas V90 of 2 MW rated power:

- Aielli $\mathrm{N}^{\circ} 3$ aerogenerators (named AE-1, AE-4, AE-7) for an area of 33.14 ha;

- Cerchio $\mathrm{N}^{\circ} 5$ aerogenerators (named AE-2, AE-3, AE5, AE-6 and AE-8) for an area of 48.12 ha.

The identified site occupies a total area of 81.26 ha.

The design of the new wind farm has been performed by means of the software WAsP (Wind Atlas Analysis and Application Program). WAsP is a program for the horizontal and vertical extrapolation of wind data. It represents a powerful tool for wind farm siting and layout design and allows to transpose with good accuracy the wind data available at some exact levels within an area with distances ranging from 10 to $50 \mathrm{~km}$ from the measuring point depending on the orographic complexity.

The program essentially takes the "climate of the wind" (i.e., speed, velocity distribution and direction) recorded by weather stations and uses it to predict the wind climate at the site where the turbines will be placed.

In particular, it allows to build up a wind map in restricted areas of interest (areas of a few square kilometers) on the basis of orographic configuration of the land, the distribution of roughness, obstacles and the distribution of the wind measured at some sites within the area, or in some cases even in neighboring sites.

The wind map, on a small scale, is necessary to identify the best sites for the wind turbines within the area under consideration and to predict the annual energy production of the wind farm, once the program is provided with the technical data regarding the chosen turbines. 


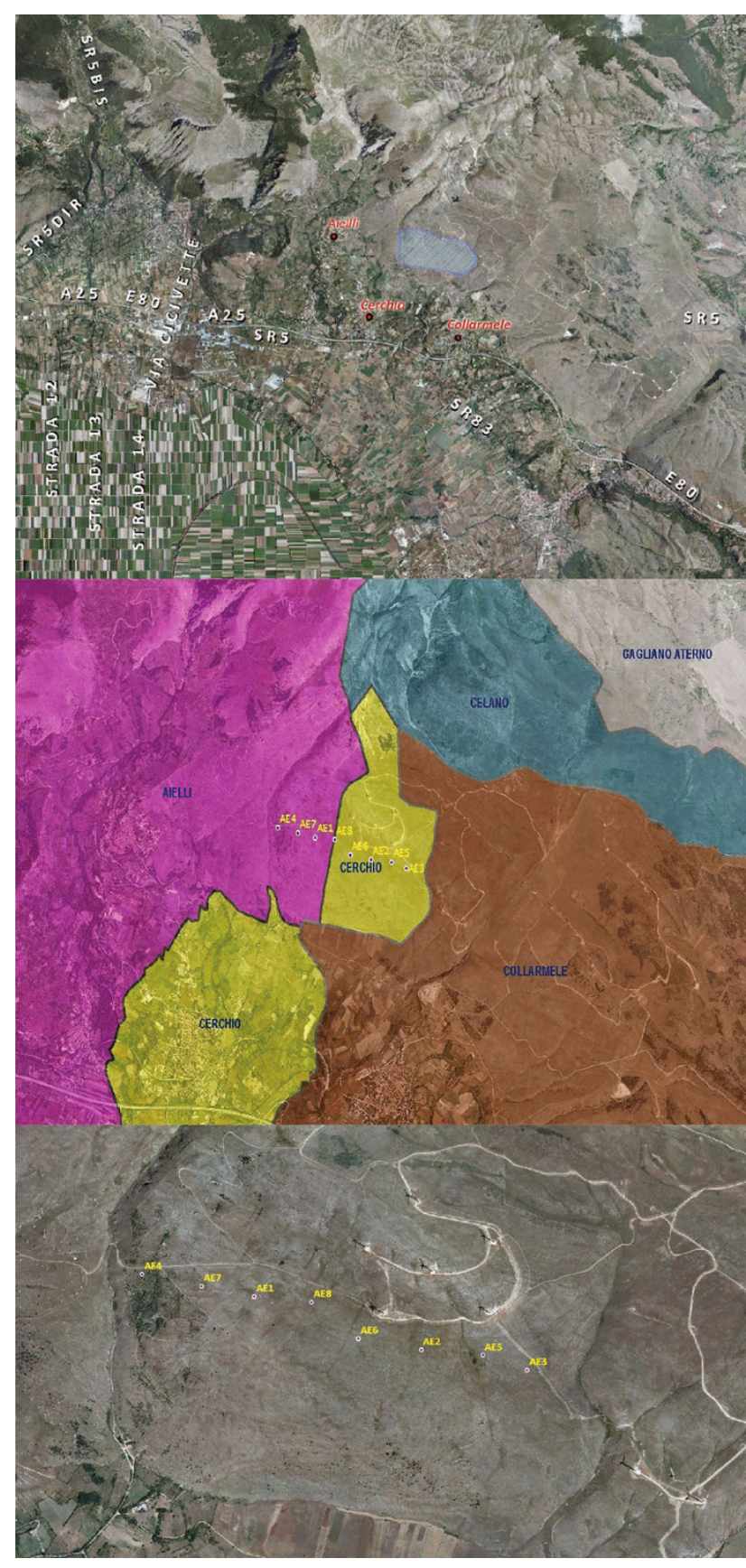

Fig. 1 Geographical map of the wind farm with municipal boundaries

The program is divided into five major blocks of calculations:

1. Analysis of the raw data. It performs the analysis of any time series of wind measurements to provide a statistical summary, as shown in Fig. 2a.

2. Generation of an atlas of wind data (wind atlas). It allows to convert the analyzed data into a climate of regional wind or simply to collect them into the atlas of the wind.
3. Estimation of the climate of the wind. Using the above calculated wind atlas or one obtained from another source (e.g., European Wind Atlas), it allows to estimate the wind climate at any specific point. By introduction of the description of the area around the planned site, the program can predict the wind climate of the current site.

4. Estimation of wind power potential. It allows to calculate the content of average total wind energy available on the site. In addition, it allows to estimate the average annual energy production of a wind turbine providing the software the power curve of the used wind turbine, as shown in Fig. 2b.

5. Calculation of energy production of the wind farm. Given the curve of the turbine and the layout of the wind farm, it allows to estimate the wake losses for each turbine and then the net annual energy production of each, and, consequently, of the whole farm (i.e., the net production).

The statistical analysis of the wind resource is performed using the Weibull law that is the most frequently used model to describe the distribution of the wind speed [2]. The probability density function (PDF) of the wind speed is given by:

$f(v)=\frac{k}{a}\left(\frac{v}{a}\right)^{k-1} \exp \left(-\frac{v}{a}\right)^{k}$,

where $f(v)$ is the probability density function of the wind speed, $v$ is the upstream wind speed, and $a$ and $k$ are, respectively, the scale parameter and the dimensionless shape parameter. According to the value of $k$, the Weibull distribution can reproduce other kinds of statistical distribution, e.g., $k=1$ exponential, $k=2$ Rayleigh and $k=3.5$ normal [11]. The reference kinetic energy flux $P_{\text {ref }}(v)$ that is incident on the surface of the wind turbine rotor surface $S_{\text {rotor }}$ can be computed as

$P_{\text {ref }}(v)=\frac{1}{2} \rho_{\text {air }} S_{\text {rotor }} v^{3}$,

where $\rho_{\text {air }}$ is the air density. It is also possible to compute the wind power density as

$P_{\mathrm{sp}}(v)=\frac{1}{2} \rho_{\text {air }} v^{3}$,

that is a useful way to evaluate the available wind resource in a potential site without taking into consideration any particular wind turbine. It is well known that the amount of power that can be extracted from the wind depends not only on the available wind energy, but also on the operating characteristics of the wind turbine. The fraction $P(v)$ that is derived by the wind turbine is computed from the reference kinetic energy flux $P_{\text {ref }}(v)$ through the power coefficient $c_{\mathrm{p}}(v)$ (that is limited by the Betz's maximum limit equal to $16 / 27$ ) as 
Fig. 2 Wind statistics (a) and wind turbine performance outputs (b) obtained through the commercial software WAsP

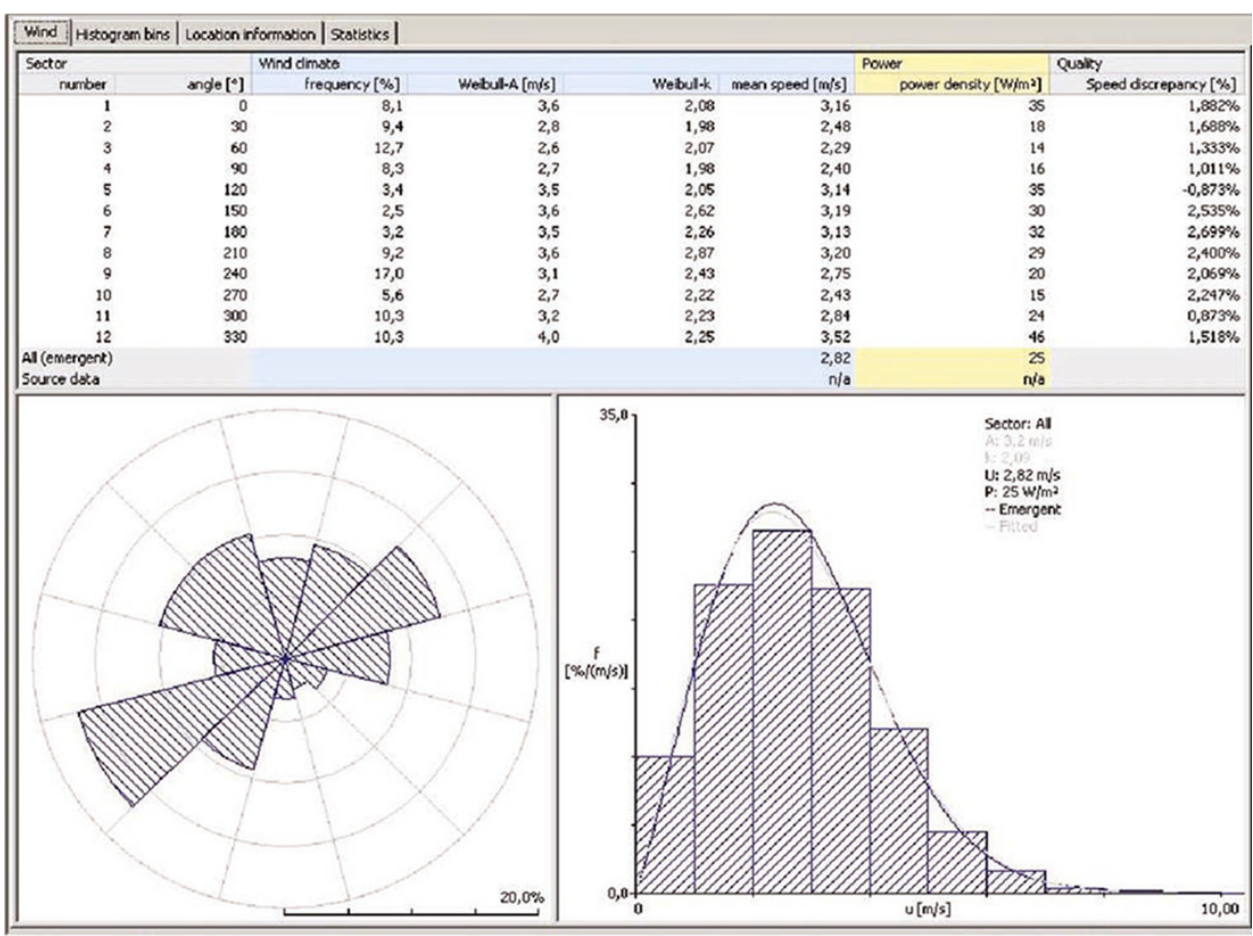

(a)

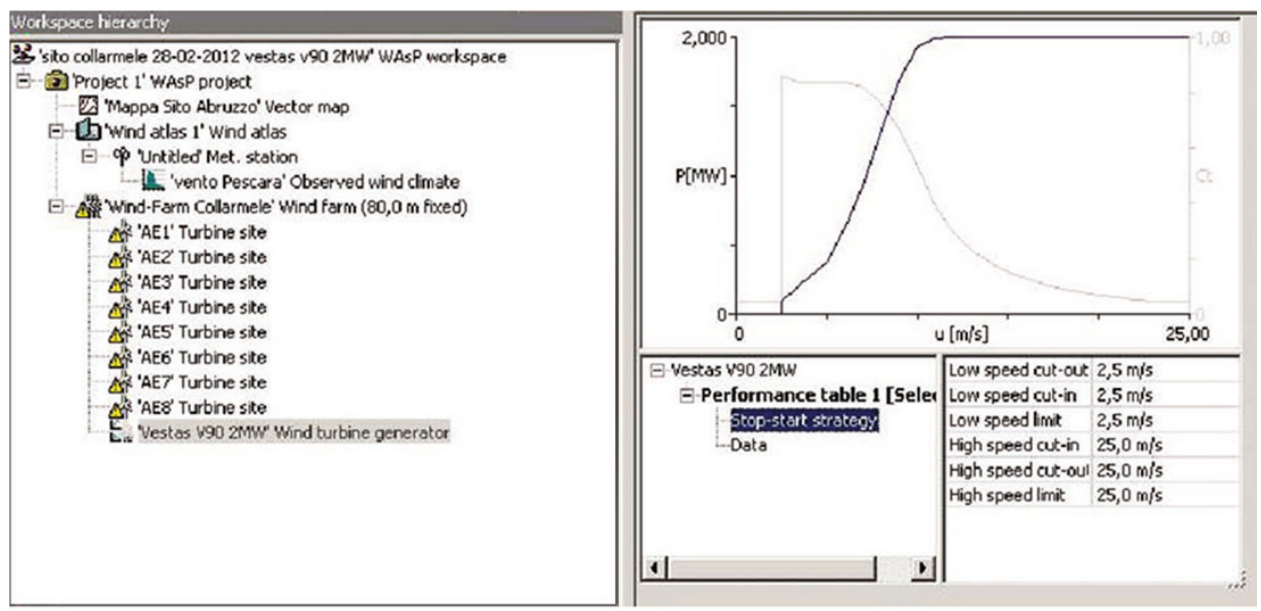

(b)
$P(v)=c_{\mathrm{p}} P_{\text {ref }}(v)$.

Finally, the gross wind energy $E_{\mathrm{g}}$ that can be extracted by a wind turbine in a period of time $T$ is computed as $E_{\mathrm{g}}=T \int_{0}^{\infty} P(v) f(v) \mathrm{d} v$.

The WAsP software allows to compute also the net wind energy $E_{\mathrm{g}}$ considering the wake losses inside the wind farm.

The selection of the wind farm site and the spotting of the wind turbines were performed on the following factors:
- wind resources;

- roughness of the terrain and obstacles;

- road access;

- orography of the region;

- accessibility to transmission and/or distribution networks;

- soil conditions;

- environmental impacts.

All the aforementioned factors have been modeled and studied through an appropriate mapping performed with the GIS software Global Mapper, starting from a digital 


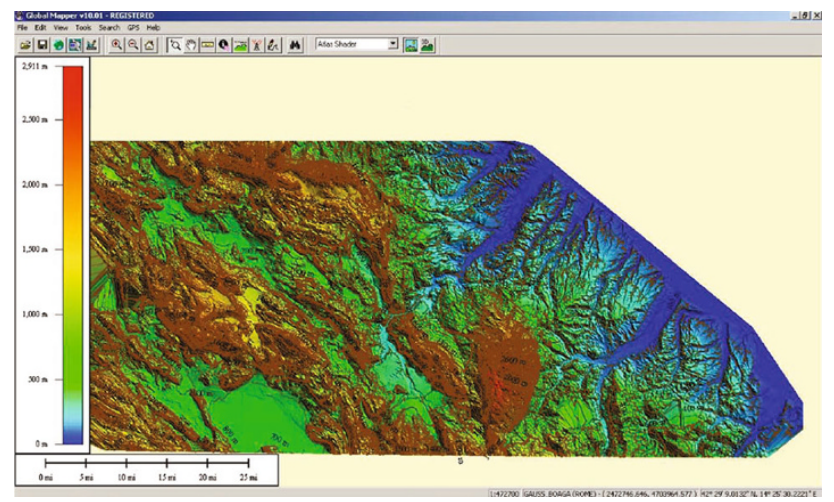

Fig. 3 GIS digital height model (DHM) of soil around the wind farm developed with the software Global Mapper. The side color bar expresses the heights of the soil in meters

height model (DHM) of the site shown in Fig. 3. The relevant results are reported in Table 1.

\section{Connection solution and ERPA criteria}

The successful realization of a distributed generation system, in our case a wind farm, depends not only on its technical feasibility, but also on the ability of the network to receive the new production. As part of its mission, since it is responsible for the transmission and dispatching activities on the HV grid across the Italian territory, Terna is required to provide a solution to connect the new plant to the network. This solution contains the works that are required on the National Transmission Network (NTN) to ensure the full producibility of the new renewable distributed generation system.

The ERPA methodology is aimed at identifying the best corridors for the routing of new the overhead power lines that are necessary for these connections. To this end, the area under study (AUS) can be characterized according to criteria which express the greater or lesser suitability to accommodate the new line. The criteria are derived from the subdivision in the following four classes of the environmental constraints and local regulations in force: Exclusions, Rejections, Problems and Attractions (ERPA). These categories are formalized by Memoranda of Understanding signed between Terna S.p.A. and the regional administrations.

The ERPA criteria are four as explained in detail in the following.

- Exclusion (E): areas in which any realization is precluded.

- Repulsion (R): areas where it is preferable to route new infrastructures only in case of the absence of alternatives or in the presence of less environmentally compatible alternatives, however, always in compliance with the agreed prescriptive framework.

- Problem (P): areas where more insights are necessary, since their allocation to the various classes established at the national level is problematic because these classes do not consider specific regional or local constraints. Therefore, further analysis is required, supported by an objective justification documented by the involved local authorities. Unlike other criteria, these are characterized by the need for further study and the absence of an automatic a priori evaluation and attribution mechanism.

- Attraction (A): areas to be preferred when possible, after verification of the carrying capacity of the area.

The ERPA criteria are subdivided into classes [Criterion class (CC)], to facilitate a more detailed assessment of the vocation of the AUS to welcome new electrical infrastructures as explained in Table 2.

In this framework, the first step of the procedure is to take into account all the constraints and local regulations that are in force on the AUS, subdivide them among the classes of the four ERPA criteria and, finally, identify the ERPA CC that are present on the AUS. When doing the subdivision work, the following rules are applied:

- When the union of the different constraints are classified under the same $\mathrm{CC}$, it is necessary to count

Table 1 Major results of the designed wind farm

\begin{tabular}{llllllllll}
\hline AE & Position Gauss-Boaga & Quote $(\mathrm{m})$ & $a$ & $k(\mathrm{~m} / \mathrm{s})$ & $v_{\mathrm{m}}(\mathrm{m} / \mathrm{s})$ & $P_{\mathrm{sp}}\left(\mathrm{W} / \mathrm{m}^{2}\right)$ & Gross $E_{\mathrm{g}}(\mathrm{GWh})$ & Net $E_{\mathrm{n}}(\mathrm{GWh})$ & Energy efficiency $(\%)$ \\
\hline 1 & $2,405,583.0-4,659,715.0$ & 1,065 & 4.1 & 2.41 & 3.68 & 49 & 2.273 & 2.006 & 88.22 \\
2 & $2,406,209.0-4,659,512.0$ & 1,071 & 4.4 & 2.44 & 3.90 & 58 & 2.610 & 2.342 & 89.68 \\
3 & $2,406,605.0-4,659,435.0$ & 1,039 & 4.2 & 2.40 & 3.75 & 53 & 2.392 & 2.229 & 93.17 \\
4 & $2,405,164.0-4,659,799.0$ & 1,044 & 4.0 & 2.39 & 3.52 & 44 & 2.056 & 1.953 & 94.95 \\
5 & $2,406,439.0-4,659,491.0$ & 1,062 & 4.3 & 2.42 & 3.86 & 57 & 2.541 & 2.310 & 90.88 \\
6 & $2,405,974.0-4,659,555.0$ & 1,075 & 4.4 & 2.44 & 3.90 & 58 & 2.605 & 2.298 & 88.19 \\
7 & $2,405,387.0-4,659,754.0$ & 1,053 & 4.1 & 2.40 & 3.59 & 46 & 2.149 & 1.925 & 89.54 \\
8 & $2,405,798.0-4,659,693.0$ & 1,090 & 4.4 & 2.43 & 3.88 & 58 & 2.579 & 2.375 & 92.09 \\
\hline
\end{tabular}


Table 2 Classes of the ERPA criteria

\begin{tabular}{|c|c|c|c|}
\hline $\begin{array}{l}\text { ERPA } \\
\text { criterion }\end{array}$ & Class & Description & Weight \\
\hline \multirow[t]{2}{*}{ Exclusion } & E1 & Constraints of absolute exclusion & 310 to 315 \\
\hline & E2 & $\begin{array}{l}\text { Constraints established by Memoranda of Understanding signed between Terna S.p.A. and the regional } \\
\text { administrations }\end{array}$ & 150 to 155 \\
\hline \multirow[t]{3}{*}{ Repulsion } & $\mathrm{R} 1$ & Areas to be considered only if no other area is available and areas are only suitable for overflight & 70 to 75 \\
\hline & $\mathrm{R} 2$ & Environmentally protected areas & 30 to 35 \\
\hline & R3 & Areas to be considered only if areas with higher environmental costs are available & 10 to 15 \\
\hline Problem & $\mathrm{P}$ & $\begin{array}{l}\text { Areas where there are critical issues supported by an objective justification documented by the involved } \\
\text { local authorities }\end{array}$ & 0 to 5 \\
\hline \multirow[t]{2}{*}{ Attraction } & A1 & Areas with higher landscape compatibility because they promote visual occlusion & -15 to 0 \\
\hline & $\mathrm{A} 2$ & Preferential areas after the check of the load capacity of the territory & -75 to -30 \\
\hline
\end{tabular}

the number of different constraints that overlap (cumulative effect).

- Some constraints that derive from different data must be, in any case, combined to form a homogeneous constraint (e.g., constraints due to different forms of urbanization constitute the same constraint and they must not be added).

The second step of the procedure is to assign an environmental weight to each ERPA CC. The determination of these weights is the result of a process of consultation with interested local authorities competent in areas where the new electrical infrastructures are insisted. In particular, to each $\mathrm{CC}$ a range of variabilities of the corresponding weight is assigned. The range of possible variability assigned to each $\mathrm{CC}$ varies between a minimum and a maximum, with the constraint that each interval cannot overlap with the intervals of other $\mathrm{CC}$ with higher or lower weight (principle of coherence of categories). Generally, the weights are positive and high for the classes of the Exclusion criterion, while they are negative for the classes of the Attraction criterion. At first, the procedure assigns automatically a uniform weight to the constraint whose value is equal to the mean of the range. Then, the operator can manually lower or rise this value on some portions of the AUS (always remaining inside the allowed range) according to specific prescriptions established through collective bargaining talks between the government, regulating bodies and unions. This is done to try to force the route of the new power lines in some portions of the territory, trying to accommodate to some requirements. Although the procedure is not completely automatic because it always calls for an operator supervision (and in fact we defined it as semi-automatic), it helps to translate the agreements obtained through negotiations in clear numerical values that can be used to route the new power lines accounting to all the constraints and without arguable unilateral choices.
The third step of the procedure requires discretizing the AUS into cells and characterizing them by an equivalent environmental crossing cost, i.e., a cost to be paid if the power line is routed through the cell.

The cell is an elementary rectangular portion of the AUS whose dimensions is a trade-off between the extension of the AUS and the accuracy of the digital layers encoding the relevant constraints taken into account. With larger AUS, one could use larger elementary cells which, however, should be small enough to reproduce the extension of the constraints on the AUS accurately.

The environmental cost is calculated by analyzing the ERPA criteria, and their weights, present on the cell itself. Thus, in this step it is necessary to perform two operations for each cell: to assign a precise weight to each $\mathrm{CC}$ on that cell (because the weight of an ERPA CC may vary from cell to cell, but it is constrained to remain inside its prescribed range of variability) and the crossing cost to the cell.

The first operation is carried out applying the aforementioned cumulative effect: the weight assigned to a $\mathrm{CC}$ over an area depends on the number of different constraints that have been grouped under the considered CC on that area.

The second operation is performed by applying the following rules:

- In case of superposition of multiple CCs in the same cell, the resulting weight is the sum of the weights of each CC (principle of proportionality between the constraints).

- The sum of the weights of more CCs that overlap on a cell and that are characterized by environmental costs lower than that of a $\mathrm{CC}$ with higher cost cannot be higher than the weight of this higher $\mathrm{CC}$, thus ensuring and maintaining the validity of the primary subdivision in classes.

- The sum of all the weights has zero as lower limit. 


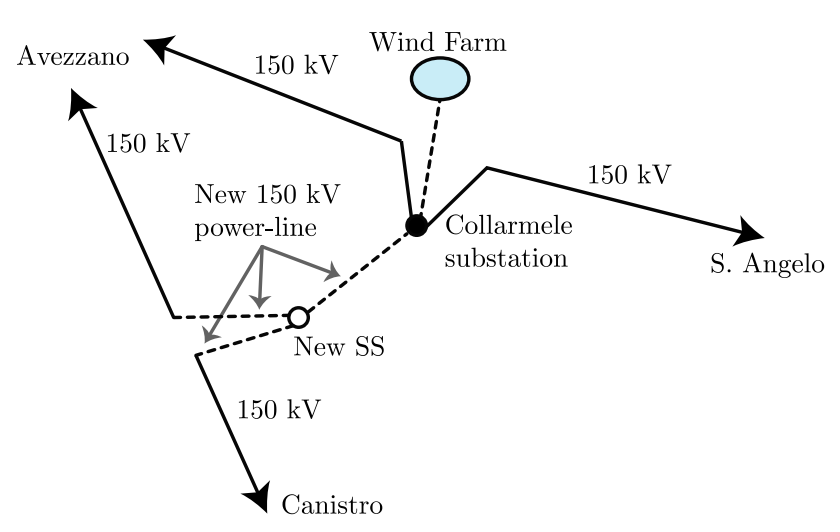

Fig. 4 Distribution diagram of the connection

The weights associated with the CCs are reported in Table 2.

The application of this procedure allows the detection of corridors characterized by lower overall environmental costs connecting two prescribed points belonging to the AUS. To this end, an algorithm has been developed that works on the GIS program ArcGIS and allows selecting contiguous geographical areas characterized by a higher level of fitness to host the infrastructures in a semi-automatic manner.

\section{Case study}

In the considered case study, taking into account the state of the network, the connection solution requires, as shown in Fig. 4:

- The construction of a new $150 \mathrm{kV}$ interconnection switching substation (SS) to be included in the existing power line going from Avezzano to Canistro.

- The connection of the wind farm to the existing collector SS named Collarmele placed on the HV power line going from Avezzano to S. Angelo.

- The construction of a new HV power line connecting the Collarmele station with the new one.

The considered constraints, and their subdivision, are reported in Table 3.

At first, it is necessary to define the AUS. The AUS is defined fixing the start and end points of the new power line to be routed. The start point is the existing primary SS named Collarmele placed on the HV line from Avezzano to S. Angelo as depicted in Fig. 4 (consequently, it is fixed), while the end point is the place in which to build the new SS to be included in the existing power line going from Avezzano to Canistro. Hence, it is necessary to make a first guess of the position of the new SS that is primarily dictated by technical and economical reasons, before any environmental constraint may be optimized in the procedure. Figure 5 shows the AUS in ArcGIS. It is possible to note that the ending point, i.e., the location of the new substation, is placed in a generic point near the existing line of Avezzano-Canistro. Furthermore, AUS is defined by the two distance vectors: $a$ and $b^{\prime}$ where $a$ is the vector connecting the two chosen extreme points of the future power line, Collarmele SS and the guessed point of the new SS to be built; $b$ is a orthogonal vector with length equal to $0.6 a$ (in the present case $a=30 \mathrm{~km}$ and $b=18 \mathrm{~km}$ ). Practical experience has proved that this choice allows the spanning of a portion of territory with an extent sufficient to locate a low-impact corridor, maintaining, in the meanwhile, the technical feasibility and the cost of the connection solution reasonable and affordable.

Successively, the algorithm requires that the AUS is discretized into cells (in the present case, rectangular patches with sides ranging between 5 and $100 \mathrm{~m}$ with aspect ratio between the sides lower than 1:5) and that each constraint is assigned to a specific layer inside ArcGIS as shown in Fig. 6.

For each cell, the program translates the constraints into ERPA CCs, assigns weights to them and evaluates the environmental crossing cost of the cell. In the present case, particular attention has been paid to the R1 constraints, especially as concerns areas of landscape and environmental value, whose weights have been manually raised in their range to account for regional requirements.

Then, the procedure looks for the environmental position of the new SS. The procedure accounts for the following constraints:

- environmental and territorial (criteria ERPA and optimization of the territorial insertion of the links with the existing Avezzano-Canistro line);

- social (distance from the urban centers);

- technical-economic (distance from the roads and inclination of the portion of territory).

The developed program searches among all the cells of the AUS, not just looking for the lowest environmental cost, but adding also four other constraints:

- optimization of the links;

- safeguarding of the urban center;

- containment of the excavations;

- accessibility of the area.

Consequently, it searches for areas that fulfill the following constraints:

- sum of all the ERPA criteria $S_{\text {ERPA }}<50$;

- distance from the existing electric lines $d_{\mathrm{el}}<1500 \mathrm{~m}$;

- distance from the urban centers $d_{\mathrm{uc}}>200 \mathrm{~m}$ (this constraint is also due to the extremely low-frequency 
Table 3 Constraints accounted for in the connection of the wind farm sited in Cerchio-Aielli
ERPA
Elements that make up the ERPA criterion
criterion

\begin{tabular}{|c|c|}
\hline \multirow[t]{2}{*}{ E1 } & Areas of military interest \\
\hline & Airports-presence of aviation areas-ports \\
\hline \multirow[t]{3}{*}{ E2 } & Cultural heritage \\
\hline & Lacustrine surfaces \\
\hline & Continuous urban fabric \\
\hline \multirow[t]{8}{*}{$\mathrm{R} 1$} & Urban discontinuous settlements \\
\hline & National and regional parks \\
\hline & Sites of UE interest \\
\hline & Areas of bear crossing \\
\hline & Areas of landscape and environmental value (regional landscape plan-Areas A) \\
\hline & Areas of high archaeological interest \\
\hline & Areas of historical, cultural, artistic and architectural interest \\
\hline & Geologic hazard areas characterized by a high hydraulic risk \\
\hline \multirow[t]{5}{*}{$\mathrm{R} 2$} & Special protection areas for birds and sites of UE interest for the natural habitat \\
\hline & Ecological networks \\
\hline & Areas of landscape and environmental value (regional landscape plan-Areas B) \\
\hline & Landscape assets enforced by an administrative directive \\
\hline & Geologic hazard areas characterized by a moderate hydraulic risk \\
\hline \multirow[t]{5}{*}{$\mathrm{R} 3$} & Bird areas \\
\hline & Areas of landscape and environmental value (regional landscape plan-Areas C) \\
\hline & Areas of moderate architectural interest \\
\hline & Vineyards and olive groves \\
\hline & $\begin{array}{l}\text { Areas classified as DOC, DOP, IGP (for wines or products with protected/controlled } \\
\text { designation) }\end{array}$ \\
\hline A1 & $\begin{array}{l}\text { Areas that facilitate the visual absorption, e.g., morphological wings and slopes facing north } \\
\text { if not falling in other criteria }\end{array}$ \\
\hline \multirow[t]{2}{*}{ A2 } & Corridors with existing electrical infrastructure and highways \\
\hline & Industrial and commercial areas, integrated development centers, technology parks \\
\hline
\end{tabular}

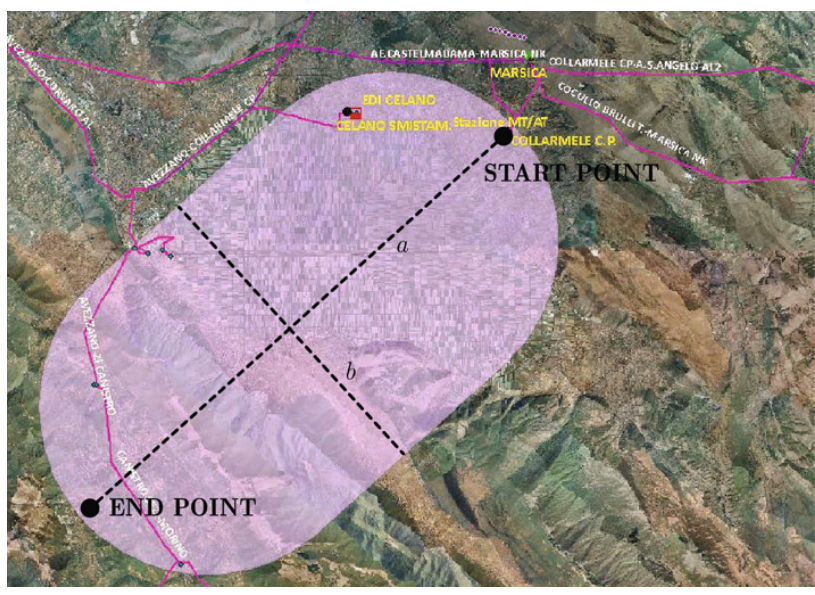

Fig. 5 Extension of the area under study exposure limits enforced by the national laws, even if active shielding could be effectively used [8-10]);

- inclination $\gamma<3^{\circ}$;

- distance $d_{\text {road }}$ from existing roads $20<d_{\text {ro }}<500 \mathrm{~m}$.

After these computations, the position of the new SS is reported in Fig. 7.

Once the new SS is placed, the program searches for the lowest environmental impact corridor to route the new power line. This procedure enables considering all the constraints that are present over the AUS, yielding a corridor which is a function of all the co-present criteria, both those which are more stringent (higher weights) and also taking into account those with lighter weighs. The final corridor with lower environmental cost and the final overhead $150 \mathrm{kV}$ power line is shown in Fig. 8. 


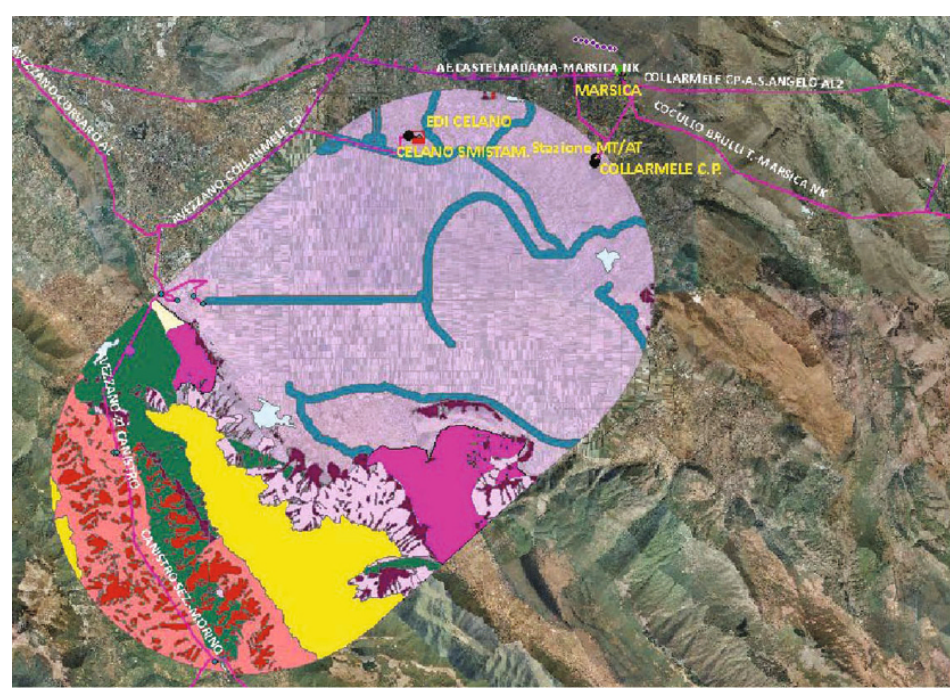

(a) Repulsion constraints

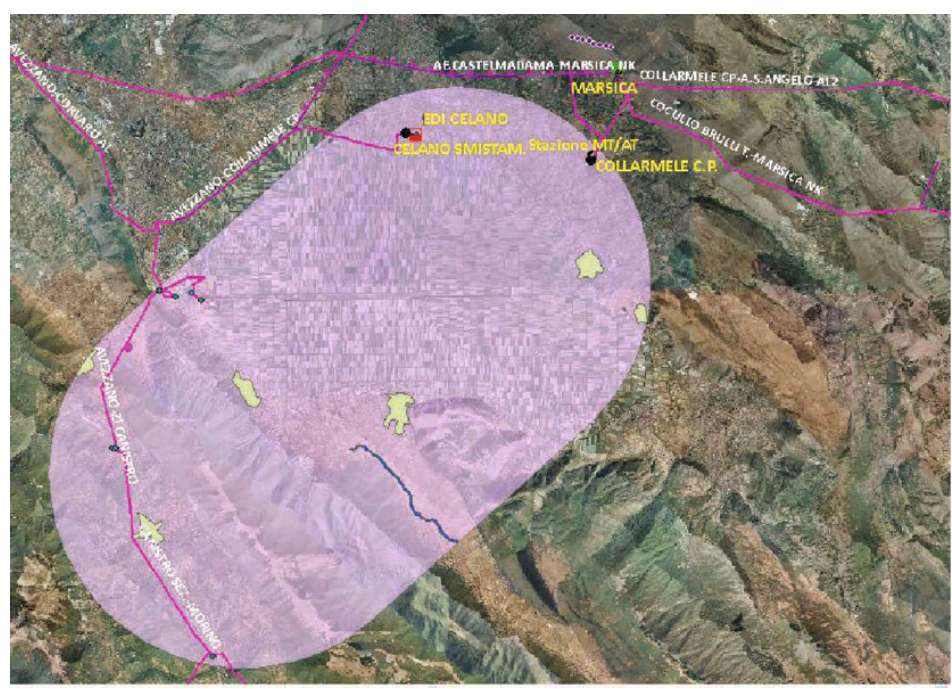

(b) Exclusion constraints

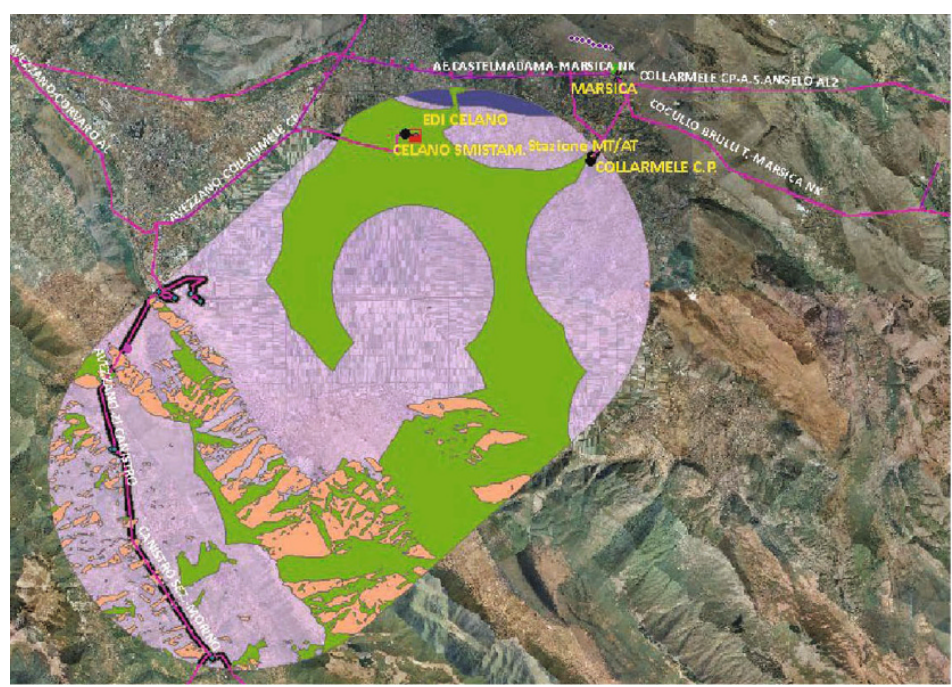

(c) Attraction constraints $\square \quad$ Areas of landscape and environmental value (Areas A)

Urban discontinuous settlements

National and regional parks

- Geologic hazard areas characterized by a high hydraulic risk

$\square \quad$ Wooded lands

- Mountains with height over $1600 \mathrm{~m}$

$\square$ Sites of UE interest

- Protected water streams

- Special protection areas for birds

- Geologic hazard areas characterized by a moderate hydraulic risk

$\square \quad$ Areas of landscape and environmental value (Areas C)

Continuous urban fabric

Cultural heritage
Areas that facilitate the visual absorption, slopes facing north $\square \quad$ Areas that facilitate the visual - absorption, morphological wings

- Electric corridors

- Highway corridors

Fig. 6 Layers encoding all the constraints present on the AUS 


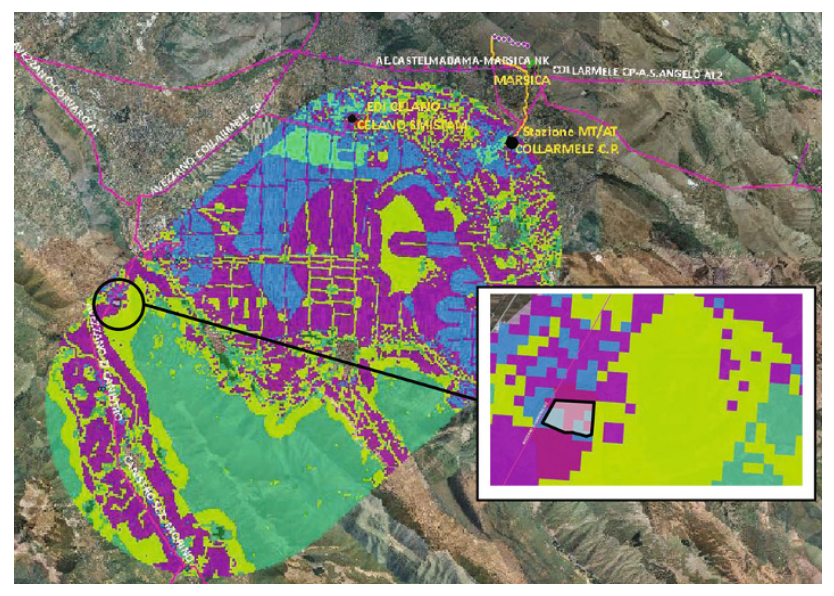

Fig. 7 Location of the new SS

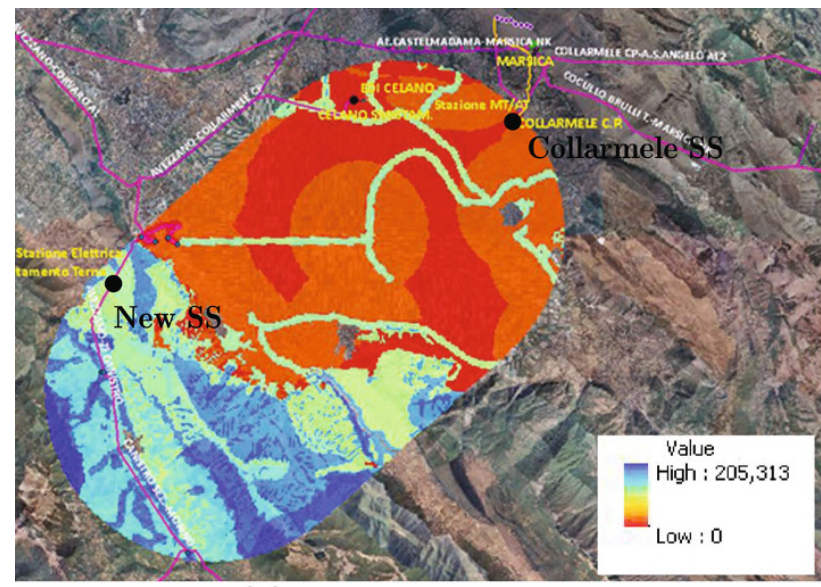

(a) Sum of the ERPA criteria

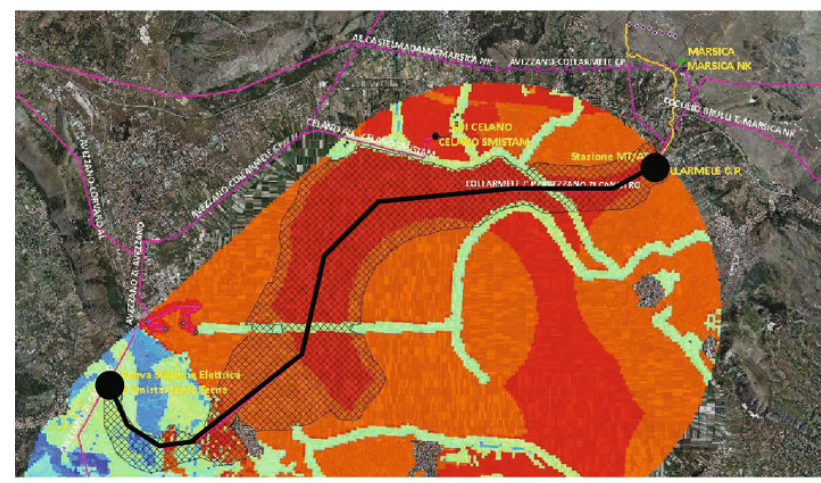

(b) Corridor with lower environmental cost

Fig. 8 Corridor with lower environmental cost and new HV $150 \mathrm{kV}$ overhead power line

\section{Conclusions}

In this paper, we investigated the suitability from an environmental point of view the methodology applied by Terna S.p.A. in siting new overhead power lines. The case study that we considered concerns the connection of a wind farm sited in the center of Italy. The methodology is named ERPA and is based on the subdivision of all the relevant constraints dictated by environmental issues and territory legislations in four classes: Exclusion, Rejection, Problem and Attraction. The subdivision is performed on structured processes and is based on the use of geographic information systems (GIS) analysis concepts. The GIS system allows to incorporate into the analysis all the relevant influence factors that are grouped into common perspectives. Then, by introducing an equivalent environmental crossing cost, the method is able to identify the corridor with lower environmental cost in a semi-automatic manner.

Open Access This article is distributed under the terms of the Creative Commons Attribution License which permits any use, distribution, and reproduction in any medium, provided the original author(s) and the source are credited.

\section{References}

1. Abam, F., Nwankwojike, B.N., Ohunakin, O.S., Ojomu, S.A.: Energy resource structure and on-going sustainable development policy in Nigeria: a review. Int. J. Energy Environ. Eng. 5(2), 1-16 (2014)

2. Adaramola, M., Oyewola, O.: Evaluating the performance of wind turbines in selected locations in Oyo state, Nigeria. Renew. Energy 36(12), 3297-3304 (2011)

3. Araneo, R., Falconi, C.: Lateral bending of tapered piezo-semiconductive nanostructures for ultra-sensitive mechanical force to voltage conversion. Nanotechnology 24(26), 265707 (2013)

4. Araneo, R., Grasselli, U., Celozzi, S.: Assessment of a practical model to estimate the cell temperature of a photovoltaic module. Int. J. Energy Environ. Eng. 5, 1-15 (2014)

5. Araneo, R., Lammens, S., Grossi, M., Bertone, S.: EMC issues in high-power grid-connected photovoltaic plants. IEEE Trans. Electromagn. Compat. 51, 639-648 (2009)

6. Araneo, R., Lovat, G., Burghignoli, P., Falconi, C.: Piezo-semiconductive quasi-1D nanodevices with or without anti-symmetry. Adv. Mater. 24(34), 4719-24 (2012)

7. Araneo, R., Bini, F., Pea, M., Notargiacomo, A., Rinaldi, A., Lovat, G., Celozzi, S.: Current-voltage characteristics of $\mathrm{ZnO}$ nanowires under uniaxial loading. IEEE Trans. Nanotechnol. 13(4) (2014)

8. Celozzi, S.: Active compensation and partial shields for the power-frequency magnetic field reduction. IEEE Int. Symp. Electromag. Compat. 1, 222-226 (2002)

9. Celozzi, S., Garzia, F.: Magnetic field reduction by means of active shielding techniques. Sustain. World 8, 79-89 (2003)

10. Celozzi, S., Garzia, F.: Active shielding for power-frequency magnetic field reduction using genetic algorithms optimisation. IEEE Proc. Sci. Meas. Technol. 151(1), 2-7 (2004)

11. de Araujo Lima, L., Bezerra Filho, C.R.: Wind energy assessment and wind farm simulation in Triunfo-Pernambuco, Brazil. Renew. Energy 35(12), 2705-2713 (2010)

12. Eddine, B., Salah, M.: Solid waste as renewable source of energy: current and future possibility in Algeria. Int. J. Energy Environ. Eng. 3(1), 17 (2012)

13. Commission, European: Renewable Energy Directive 2009/28/ EC. In: Proceedings of European Parliament and of the Council, Technical Report (2009) 
14. European Commission: Communication from the Commission to the European Parliament, the Council, the European Economic and social committee and the Committee of the regions: a roadmap for moving to a competitive low-carbon economy in 2050 . Technical report, European commission SEC, 288 final (2011)

15. European Commission: Communication from the Commission to the European Parliament, the Council, the European Economic and social committee and the committee of the regions: energy roadmap 2050, Technical report, European commission COM, 885 final (2011)

16. European Commission: Communication from the Commission to the European Parliament, the Council, the European economic and social committee and the committee of the regions: impact assessment-energy roadmap 2050, Technical report, European commission SEC, 1565 final (2011)

17. Ferreira, J.V., Viana, H., Esteves, B., Cruz Lopes, L.P., Domingos, I.: Life cycle assessment of residual forestry biomass chips at a power plant: a Portuguese case study. Int. J. Energy Environ. Eng. 5(2), 1-7 (2014)

18. Fischer, T.B.: Theory and Practice of Strategic Environmental Assessment. Earthscan, London (2007)

19. Flodberg, K., Blomsterberg, A., Dubois, M.C.: Low-energy office buildings using existing technology: simulations with low internal heat gains. Int. J. Energy Environ. Eng. 3(1), 1-9 (2012)

20. Hurtado, A., Eguilior, S., Recreo, F.: Methodological development of a probabilistic model for $\mathrm{CO}_{2}$ geological storage safety assessment. Int. J. Energy Environ. Eng. 5(2), 1-10 (2014)

21. Jacobsen, H.K., Pade, L.L., Schrder, S.T., Kitzing, L.: Cooperation mechanisms to achieve EU renewable targets. Renew. Energy 63, 345-352 (2014)

22. Lal, S., Raturi, A.: Techno-economic analysis of a hybrid minigrid system for Fiji islands. Int. J. Energy Environ. Eng. 3(1), 1-10 (2012)

23. Lean, H.H., Smyth, R.: Will policies to promote renewable electricity generation be effective? Evidence from panel stationarity and unit root tests for 115 countries. Renew. Sustain. Energy Rev. 22, 371-379 (2013)

24. Lucchetti, E., Barbier, J., Araneo, R.: Assessment of the technical usable potential of the TUM Shaft Hydro Power plant on the Aurino River, Italy. Renew. Energy 60, 648-654 (2013)
25. Melikoglu, M.: Vision 2023: feasibility analysis of Turkey's renewable energy projection. Renew. Energy 50, 570-575 (2013)

26. Menegaki, A.N.: Growth and renewable energy in Europe: benchmarking with data envelopment analysis. Renew. Energy 60, 363-369 (2013)

27. Pang, X., Mörtberg, U., Brown, N.: Energy models from a strategic environmental assessment perspective in an EU context: what is missing concerning renewables? Renew. Sustain. Energy Rev. 33, 353-362 (2014)

28. Quinonez-Varela, G., Cruden, A., Graham, C., Punton, B., Blair, L., Thomson, J.: A GIS/PSS planning tool for the initial grid connection assessment of renewable generation. Renew. Energy 32(5), 727-737 (2007)

29. Rinaldi, A., Araneo, R., Celozzi, S., Pea, M., Notargiacomo, A.: The clash of mechanical and electrical size-effects in $\mathrm{ZnO}$ nanowires and a double power law design concept for piezoelectric and piezotronic devices. Adv. Mater. (2014). doi:10.1002/adma.201401026

30. Shafiullah, G., Amanullah, M., Ali, A.S., Jarvis, D., Wolfs, P.: Prospects of renewable energy: a feasibility study in the Australian context. Renew. Energy 39(1), 183-197 (2012)

31. Sharma, P., Harinarayana, T.: Enhancement of energy generation from two layer solar panels. Int. J. Energy Environ. Eng. 3(12), 1-9 (2012)

32. Sharma, P., Harinarayana, T.: Solar energy generation potential along national highways. Int. J. Energy Environ. Eng. 4(16), 1-13 (2013)

33. Sims, S., Dent, P.: High-voltage overhead power lines and property values: a residential study in the UK. Urban Stud. 42(4), 665-694 (2005)

34. Whitworth, C.C., Duller, A.W.G., Jones, D., Earp, G.: Aerial video inspection of overhead power lines. Power Eng. J. 15(1), 25-32 (2001)

35. Zangl, H., Bretterklieber, T., Brasseur, G.: Energy harvesting for online condition monitoring of high-voltage overhead power lines. In: Proceedings of Instrumentation and Measurement Technology Conference, 2008, IMTC 2008. IEEE, pp. 1364-1369 (2008) 